\title{
EVOLUÇÃO FAVORÁVEL DE UM CASO DE CISTICERCOSE CEREBRAL OBSERVADO DURANTE 10 ANOS
}

\author{
Paulo Pinto Pupo
}

J. Baptista dos REIS

A cisticercose encefálica constitui, em nosso meio, pela sua freqüência, sério problema médico. O prognóstico, na grande maioria dos casos, apresenta-se sombrio; a generalidade dos autores por nós consultados, assim como nossa experiência desde 1933 no Hospital de Juqueri e depois no Serviço de Neurologia da Escola Paulista de Medicina ${ }^{1}$; levaram-nos a essa convicção.

A presença do parasito no parênquima nervoso ou nas leptomeninges determina, em geral, reações locais intensas, sob a forma de meningoencefalite crônica com grande destruição do elemento neuronal do córtex cerebral, e reações a distância, sob a forma de meningite crônica, mais freqüentemente localizada na base do encéfalo, acarretando progressivo bloqueio à circulação do líqüido cefalorraqueano. No primeiro caso, a sintomatologia clínica evidencia um quadro de decadência mental global, progressiva e inexorável, associada comumente a convulsões epileptiformes; no segundo, predomina a sintomatologia devida ao bloqueio da circulação do líquor, e então é a síndrome de hipertensão intracraniana a que mais chama a atenção. Ao lado dêsses casos, há aquêles, mais raros, em que o cisticerco livre dentro dos ventrículos pode bloquear o aqueduto de Sylvius ou o $4^{\circ}$ ventrículo, determinando síndrome clínica muito peculiar, isto é, surtos de hipertensão intracraniana aguda que cede espontâneamente, sintomatologia Jabiríntica e auditiva, ao lado de alterações do líquor (hipercitose com eosinófilos, aumento discreto das proteínas totais, porém evidente das globulinas, reação de fixação de complemento para cisticercos positiva em presença da negatividade da reação de Wassermann), a qual, reconhecida em tempo útil, pode levar o médico a uma terapêutica neurocirúrgica com possibilidade de êxito.

0 caso que relatamos apresenta duas particularidades dignas de registro: primeiro, a evolução em cujo decurso se processou a calcificação de

'Trabalho apresentado ao Departomento de Neuro-Psiquiatria da Associação Paulista de Medicina, em 5 fevereiro 1953. 
cisticercos bem como a cura clínica, evolução esta bastante diversa da generalidade dos casos; segundo, a cooperação da paciente e seus familiares, que permitiu esta extensa observação, durante um período de 10 anos, com exames seriados, inclusive o do líqüido cefalorraqueano, que inicialmente foi feito duas vêzes por ano e ulteriormente uma só vez.

Observação - A. A. M., com 5 anos de idade, reg. 814, em 20-5-1943. A paciente, que residia em cidade do Interior do Estado de São Paulo, fôra portadora de tênia. Há três meses teve início sua moléstia, que se manifestava por frequientes crises convulsivas de tipo bravais-jacksoniano, iniciando-se pelo membro superior direito. (OS exames clínico geral, psíquico e neurológico nada revelaram de anormal, exceto vivacidade bilateral dos reflexos profundos. Exame parasitológico das fèes negativo; radiografia do crânio normal. O exame do líquuidu cefalorraqueano revelou alterações que caracterizam o quadro sugestivo de cisticercose encefálica, conforme podemos verificar no quadro anexo. Foi instituíla it terapêutica pelo luminal e feitas 8 aplicações de radioterapia profunda sôbre o hemisfério cerebral esquerdo. A evolução do caso processou-se de forma como passaremos a expor resumidamente:

Até setembro de 1943 apresentou cinco convulsões; continua sob medicação barbitúrica. Até janeiro de 1944 teve apenas uma convulsão. Até março de 1944 sòmente teve, por duas vézes, "ameaços" (sic), consistentes em fuga rápida da consciência, sem queda ou convulsões; foi associado à medicação barbitúrica o Hidantal, sendo iniciado o tratamento pelo extrato etéreo de feto macho, na dose de $1 \mathrm{~g}$ por dia, durante 10 dias consecutivos por mês; foram feitas 10 aplicações de ionização transcerebral com iodeto de potássio. Até agôsto de 1944 sòmente uma crise convulsiva; prossegue ó tratamento com o feto macho, que está sendo bem tolerado. Até janeiro de 1946, prossegue muito bem, sem ter tido crise convulsiva alguma; estado geral bom, ótimo desenvolvimento sômato-psíquico. Èn junho de 1946, ainda muito bem, sem crises convulsivas; bom aproveitamento nos estudos, muito bons o comportamento e a adaptação no meio escolar; o tratamento pelo luminal, instituído desde o início, foi modificado para $0,05 \mathrm{~g}$ em dias alternados. Em janeiro de 1947 vai passando òtimamente bem, sem crises convulsivas ou outras de qualquer tipo; intelectualmente muito bem, assim como sob o ponto de vista afetivo, de humor e de sociabilidade. Em julho de 1947 e em janeiro de 1948 estado geral muito bom, não tendo tido crises convulsivas. Em julho de 19.48: há 20 dias, pela manhã, por dois dias consecutivos, teve crises de perda momentânea da consciência, com respiração forçada; foi restabelecida a medicação barbitúrica diária. Em janeiro de 1949: ótimo desenvolvimento sômato-psíquicn; não apresentou mais manifestações mórbidas, sendo progressivamente suspensa tôda a medicação. Em janeiro de 1950: muito bem de saúde; crescimento acentuado; estado psíquico muito bon; exames clínico geral, neurológico e psíquico normais: continua sem qualquer medicação. Em janeiro de 1951: passou muito bem de saúde, sem ter tido qualquer manifestação convulsiva; foi aprovada nos exaınes, tendo passado para a $2^{\mathrm{a}}$ série ginasial; como ainda persistisse pleocitose no líquor, foi aconselhada nova série de ionização transcerebral com iodeto de potássio. Em janeiro de 1952: perfeitamente bem do ponto de vista somático e psíquico; está agora com a aparência de moça; menstruada regularmente. Fm janeiro de 1953: continua muito bem; foi feita nova radiografia do crânio que, em contraste conı aquela feita em 1943, mostrou quatro nódulos calcificados sugerindo cisticercos encefálicos calcificados.

Exames complementares - Os exames seriados do líqüido cefalorraqueano podem ser confrontados no quadro 1. 


\begin{tabular}{|c|c|c|c|c|c|c|c|c|c|c|}
\hline \multirow[t]{2}{*}{ GNo } & \multicolumn{3}{|c|}{ C1TOLOGLA } & \multirow[b]{2}{*}{ Eos. } & \multirow{2}{*}{$\begin{array}{l}\text { Protel- } \\
\text { nas }\end{array}$} & \multirow{2}{*}{$\begin{array}{c}\text { OLOEVLINAS } \\
\text { Pandy }\end{array}$} & \multicolumn{2}{|c|}{ REACOES COLOIDAIS } & \multirow{2}{*}{\multicolumn{2}{|c|}{$\begin{array}{c}\text { REACFES SEROLOGICAS } \\
\text { St. CISt ICercose }\end{array}$}} \\
\hline & तब & Mon. & P1asm. & & & & Denjolm & T.Ara & & \\
\hline 1943 & 25 & 97 & 3 & & 0,32 & + & 22211.22221 .00000 .0 & $+s$. & + & $1+c / 0,2$ \\
\hline $104 !$ & 21 & 98 & 2 & - & 0,32 & + & 00000.02222 .00000 .0 & +1. & - & $+c / 0,2$ \\
\hline 1945 & 18 & 200 & - & & 0,14 & - & 00000.02100 .00000 .0 & - & $=$ & $+c / 1,0$ \\
\hline 2946 & 22 & 94 & 5 & 1 & 0.29 & + & 00000.02220 .00000 .0 & - & - & - \\
\hline 1947 & 15 & 98 & 2 & - & 0,18 & - & 00000.02210 .00000 .0 & $=$ & $=$ & - \\
\hline 2948 & 28 & 96 & 3 & 2 & 0,17 & - & $00000,02220,00000.0$ & - & - & - \\
\hline 1949 & 20 & 100 & - & - & 0.25 & + & 00000.02220 .00000 .0 & $=$ & - & $=$ \\
\hline 1950 & 26 & 100 & . & .. & 0,18 & - & 00000.02200 .00000 .0 & - & - & - \\
\hline 1951 & 24 & 100 & $\dot{-}$ & - & 0,18 & $=$ & 00000.02200 .00000 .0 & $=$ & - & $=$ \\
\hline 1952 & 2 & 99 & 1 & - & 0,16 & - & 00000.02200 .00000 .0 & $=$ & $=$ & - \\
\hline 2953 & 12 & 98 & - & 2 & 0,17 & - & 00000.02200 .00000 .0 & $=$ & $=$ & $=$ \\
\hline
\end{tabular}

Caso A. A. M. - Quadro mostrando os resultados comparativos dos exames de líquiido cefalorraqueano feitos durante 10 anos. Legenda: Mon., linfomononucleares; Plasm., plasmócitos; Eos., eosinófilos; St., reação de Steinfeld. A colhe:ta do LCR foi feita sempre por via cisternal, doente deitado. A medida da pressão e o aspecto e côr foram normais. As taxas de cloreto e glicose estiveram sempre dentro dos limites da normalidade. As reações de Wassermann e de floculação de Eagle foram sempre negativas.

Radiografias de crânio (Dr. Celso Pereira da Silva) - Craniograma (26-5-1943): Paredes cranianas delgadas e de contornos regulares; suturas cranianas diastasadas nas duas tábuas; sincondrose esfenoccipital presente; seios frontais ainda não escavados; seios maxilares de pequenas dimensões; trunsparência normal dos seios crânio-faciais; seios esfenoidais parcialmente pneumatizados; impressões digitais com aspecto normal; sela túrcica de contornos regulares, com diâmetro de profundidade predominante; valores normais dos diârnetros selares (A.P. $8 \mathrm{~mm}$; Prof. $7 \mathrm{~mm}$ ); ausência de sombras calficadas patológicas intracranianas e de sinais radiológicos gerais de hipertensão intracraniana. Pueumencefalograma (11-1-1944): Punção SOS; líquor retirado $33 \mathrm{ml}$; $\not \mathbf{r}$ injetado ativamente $18 \mathrm{ml}$; reações imediatas, vômitos; escassa repleção gasosa dos ventrículos laterais; $3^{\circ}$ ventrículo de situação mediana; espaços subaracnóideos do córtex bem contrastados nos dois hemisférios, onde apresentam calibre normal; cisternas basiais normais. Craniograma (21-1-1953) -- Crânio simétrico, apresentando paredes delgadas e de contornos regulares em suas duas tábuas; suturas cranianas diastasadas ná tábua externa, mas não disjuntas; seios crânio-faciais de dimensões e de transparência normais; pneumatização simétrica das mastóides; pirâmides petrosas simétricas e de contornos regulares; aspecto normal dos sulcos vasculares; sela túrcica de contornos nítidos e regulares; valores normais dos diâmetros selares (A.P. $11 \mathrm{~mm}$; Prof. $8 \mathrm{~mm}$ ); presença de quatro nódulos calcificados, o maior medindo cêrca de $5 \mathrm{~mm}$ de diâmetro, bem delimitados em seus contornos e situados na região parietal esquerda, próximos à linha mediana - calcificações patológicas, províveis cisticercos encefálicos calcificados. Életrencefalograma ( $\mathrm{n}^{\circ}$ 961, em 20-1-1953: Traçado em condiçōes técnicas satisfatórias, exaustivamente feito em vigília e durante o sono barbitúrico; atividade elétrica cerebral regular e simétrica, muito pobre, por ondas de reduzido potencial $(10$ a $15 \mathrm{mV})$ e frequiência em tôrno de $12 \mathrm{c} / \mathrm{s}$; com a hiperpnéia, lentificação frustra do trạ̧ado e eclosão de raros surtos de ondas $3-4 \mathrm{c} / \mathrm{s}$, bilaterais e síncronas, de curta duração; não há sinais de processo lesional cerebral ativo atual. Em conclusão, EEG de repouso dentro dos limites da normalidade; com ativação pela hiperpnéia, alterações frustras, no limiar da normalidade para a idade da paciente. 


\section{COMENTARIOS}

No presente caso, o diagnóstico de cisticercose encefálica feito em 1943 foi amplamente comprovado pela persistência da síndrome liquórica que lhe é bastante peculiar e, finalmente, pela calcificação dos parasitos mortos no encéfalo, o que foi verificado por radiografia feita recentemente.

As manifestações clínicas de convulsões, que tinham caráter focal indiscutível, se espaçaram e se tornaram menos intensas, desaparecendo após ano e meio de tratamento, com um único e fugaz recrudescimento em 1948. O desenvolvimento psíquico e somático foi perfeito, fato digno de nota levando-se em consideração que a cisticercose atingiu êste encéfalo já aos 5 anos de idade, portanto em plena fase de evolução. A diminuição progressiva de intensidade das alterações do líqüido cefalorraqueano, coincidente com a calcificação de quatro dos parasitos encefálicos, fazem prever sua completa normalização com a morte e conseqüente calcificação de outros parasitos ainda existentes. O eletrencefalograma, não evidenciando foco epileptógeno ativo na corticalidade cerebral, corrobora também na esperança dessa ulterior cura completa.

Fizemos, no decorrer dêstes 10 anos, terapêutica pelo extrato etéreo de feto macho de modo intensivo e persistente (por mais de um ano seguido), assim como duas séries de ionizações ioduradas transcerebrais. Se tais tratamentos tiveram influência na evolução do caso ou não, é uma questão que não nos atrevemos a responder. Propendemos mais para a última hipótese, cépticos que somos quanto à terapêutica clínica da cisticercose encefálica.

\section{RESUMO}

0 caso apresentado refere-se a uma paciente, observada ininterruptamente desde os 5 anos até aos 14 anos de idade, cuja moléstia evoluiu para a cura clínica comp'eta. $\mathrm{O}$ quadro inicial caracterizou-se pelo aparecimento de crises convulsivas de tipo bravais-jacksoniano reiteradas, em menina anteriormente sadia, que havia sido portadora de tênia. A radiografia do crânio foi normal, porém o exame do líqüido cefalorraqueano revelou hipercitose, com presença de eosinófilos em algumas amostras, aumento das proteínas e, mais particularmente, das globulinas, além de positividade da reação de fixação de complemento para cisticercos, possibilitando assim o diagnóstico etiológico. $O$ curso clínico foi acompanhado cuidadosamente com exames clínicos e do líquor cada 6 meses. Foram feitos tratamento geral anticonvulsivante (hidantoinatos e barbitúricos) e terapêutica visando em particular os cisticercos (extrato etéreo de feto macho na dose diária de $1 \mathrm{~g}$, na freqüência de 10 dias por mês, durante um ano, além de ionizações transcerehrais com iodeto de potássio). O desaparecimento das crises fêz-se logo no segundo ano de evolução, com ligeira recidiva em 1948, e os exames do líquor mostraram decréscimo progressivo da pleocitose, normalização das proteínas, negativação da reação de fixação de comple- 
mento para cisticercos. Por último, a radiografia do crânio, que inicialmente era normal, mostrou quatro cisticercos calcificados. 0 eletrencefa'ograma, feito em 1953, não evidenciou qualquer foco lesional cerebral convulsiógeno ativo. A evolução somática e mental da paciente foi ótima, tornando-se hoje uma moça inteligente, boa estudante, perfeitamente bem integrada no ambiente familiar e social em que vive.

\section{SUMMARY}

The authors make general considerations about the clinical picture and prognosis of cerebral cysticercosis and relate a case with favorable evolution for 10 years, which had a complete cure.

The patient, a 5 year old girl, was first seen due to repeated Jacksonian seizures. She had been healthy but had had tape-worm. Craniogram was normal, and spinal fluid examination revealed hypercytosis, with eosinophils, increased proteins, particularly the globulins, and positive reaction for cysticercosis. The patient was carefully re-examined during these 10 years, and clinical examinations and spinal fluid tests were performed every six months. She received general anti-epileptic treatment (hidantoinate and barbiturate) and specific treatment for cysticercus.

The seizures disappeared after 2 years of treatment, with a slight recurrence in 1948, and the spinal fluid examinations showed progressive decrease in the cell count, normalization of proteins and the reaction for cysticercus became negative. The craneogram, which was normal beforei now showed four calcified cysticercus. 'The EEG made in 1953 showed no evidence of focal lesion. The somatic and mental development of the patient was normal.

\section{BIBLIOGRAFIA}

1. Pupo, P. P.; Cardoso, W.; Reis, J. B.; Pereira da Silva, C. - Sôbre a cisticercose encefálica. Esiudo clínico, anátomo-patológico, radiológico e do líquiido cefalorraqueano. Arq. Assist. Psicopatas de São Paulo, 10-11:3-123, 1945. 2. Pupo, P. P.; Mattos Pimenta, A. - Cisticercose do IV ventrículo. Considerações anátomoclínicas e sôbre a terapêutica cirúrgica. Arq. Neuro-Psiquiat., 7:274-291 (setembro) 1949. 